
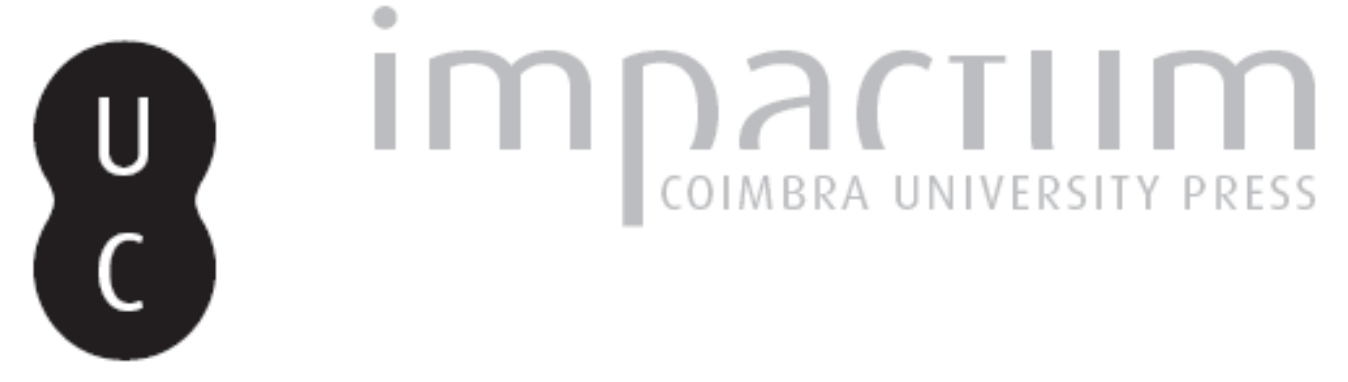

\title{
Riscos para a saúde num ambiente térmico frio: o vestuário e uma onda de frio Autor(es): $\quad$ Talaia, Mário
}
Publicado por: Associação Portuguesa de Riscos, Prevenção e Segurança; Imprensa da Universidade de Coimbra

URL persistente:

URI:http://hdl.handle.net/10316.2/39728

DOI:

DOI:https://doi.org/10.14195/1647-7723_23_4

Accessed : $\quad$ 26-Apr-2023 13:04:39

A navegação consulta e descarregamento dos títulos inseridos nas Bibliotecas Digitais UC Digitalis, UC Pombalina e UC Impactum, pressupõem a aceitação plena e sem reservas dos Termos e Condições de Uso destas Bibliotecas Digitais, disponíveis em https://digitalis.uc.pt/pt-pt/termos.

Conforme exposto nos referidos Termos e Condições de Uso, o descarregamento de títulos de acesso restrito requer uma licença válida de autorização devendo o utilizador aceder ao(s) documento(s) a partir de um endereço de IP da instituição detentora da supramencionada licença.

Ao utilizador é apenas permitido o descarregamento para uso pessoal, pelo que o emprego do(s) título(s) descarregado(s) para outro fim, designadamente comercial, carece de autorização do respetivo autor ou editor da obra.

Na medida em que todas as obras da UC Digitalis se encontram protegidas pelo Código do Direito de Autor e Direitos Conexos e demais legislação aplicável, toda a cópia, parcial ou total, deste documento, nos casos em que é legalmente admitida, deverá conter ou fazer-se acompanhar por este aviso.

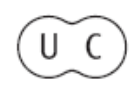




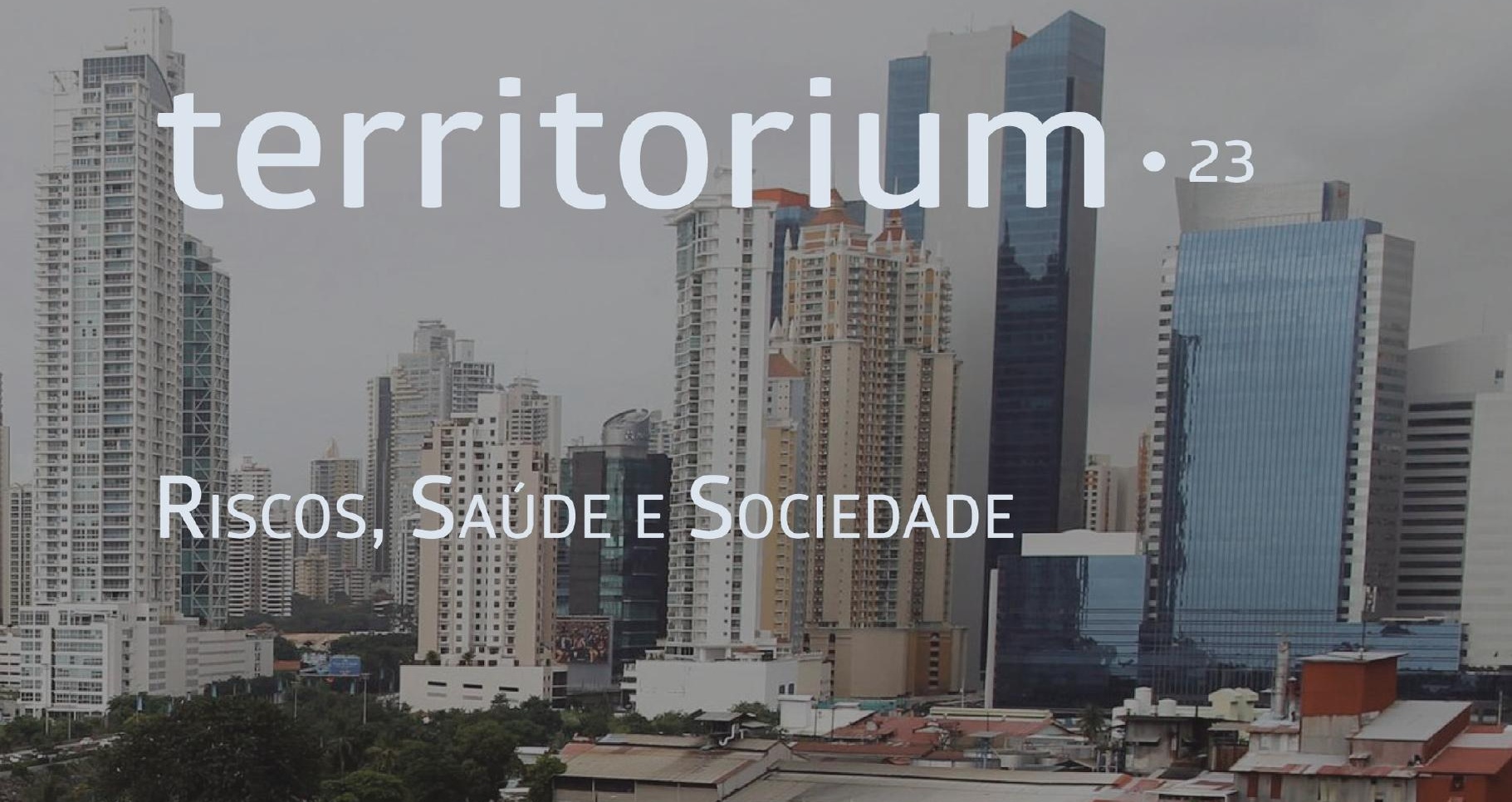

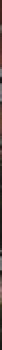

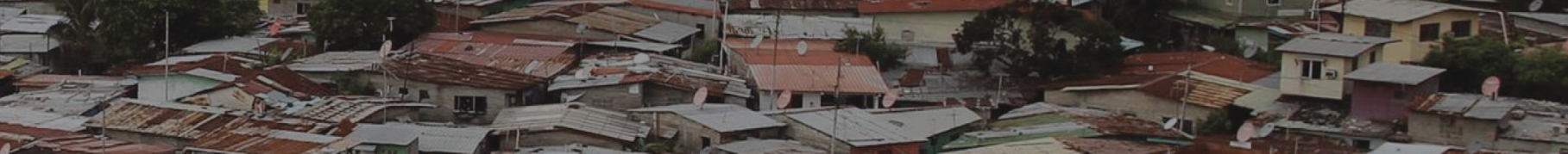

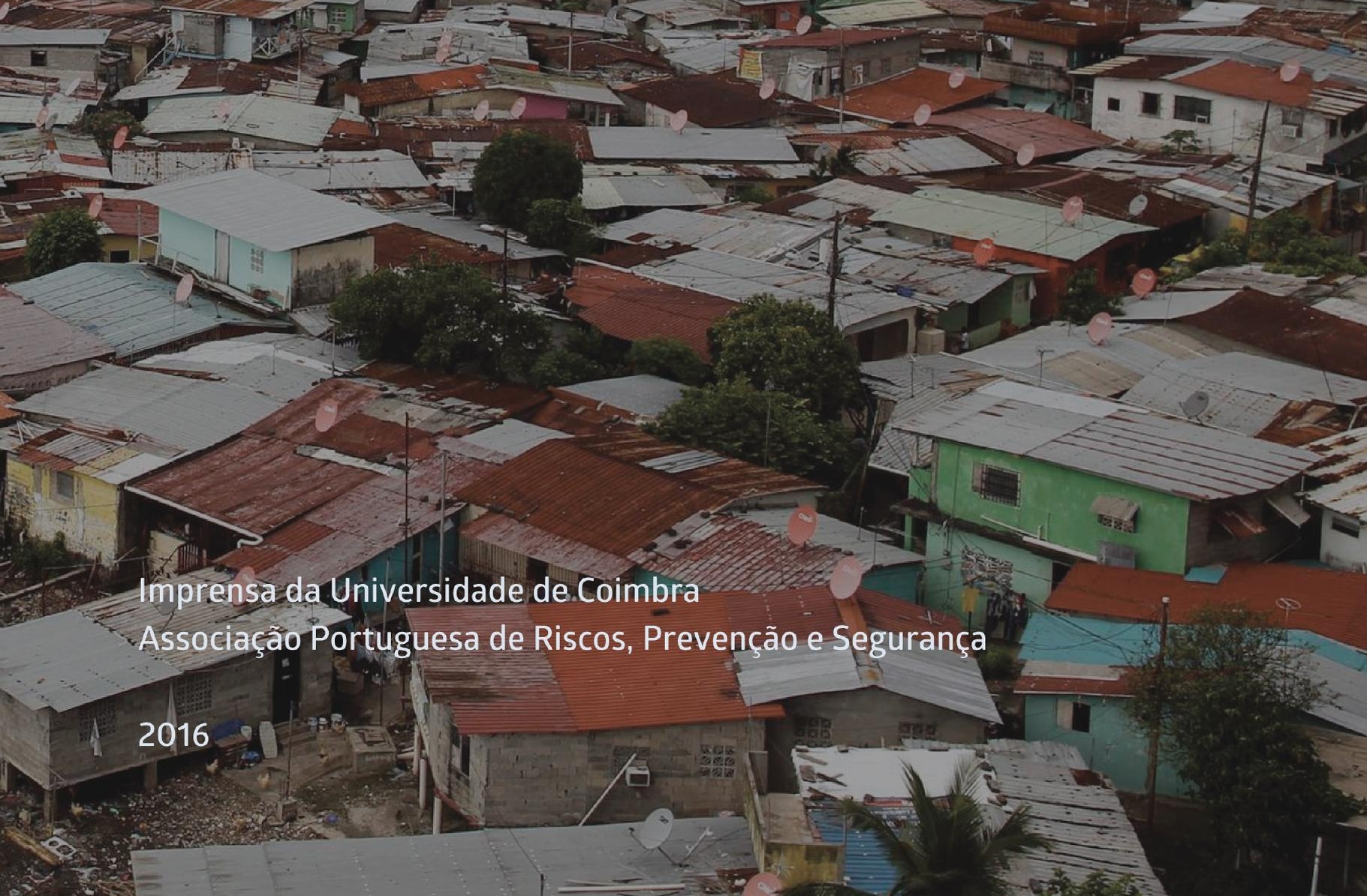




\section{RISCOS PARA A SAÚDE NUM AMBIENTE TÉRMICO FRIO: O VESTUÁRIO E UMA ONDA DE FRIO*}

HEALTH RISKS IN A COLD THERMAL ENVIRONMENT: CLOTHING AND A COLD WAVE

Mário Talaia

Departamento de Física da Universidade de Aveiro mart@ua.pt

\section{RESUMO}

Este trabalho apresenta um estudo de caso para ambiente térmico frio a céu aberto numa região de coordenadas geográficas $40.67^{\circ} \mathrm{N}$ e $8.45^{\circ} \mathrm{W}$ no lugar da Sernada do Vouga do concelho de Águeda e Distrito de Aveiro e foi realizado na primeira quinzena de fevereiro de 2015. Foi mantido o isolamento térmico do vestuário. Foram usados indicadores de sensação térmica e de isolamento térmico. Os resultados obtidos mostram que as sensações térmicas reais estão em concordância com as sensações térmicas previstas e que o isolamento térmico do vestuário deve ser adaptado para as condições termohigrométricas do ar húmido, de modo a evitar a falência do corpo.

Palavras-chave: Ambiente térmico frio, hipotermia, índice EsConTer, isolamento do vestuário, mapas de tempo.

\section{ABSTRACT}

This paper presents a case study for cold thermal environment in the open air in a region of geographic coordinates $40.67^{\circ} \mathrm{N}$ e and $8.45^{\circ} \mathrm{W}$ conducted in first fortnight of February 2015 in Sernada do Vouga, municipality of Águeda, district of Aveiro. It was kept insulated clothingThermal insulation of the clothing was kept. Thermal sensation indicators and thermal insulation indicators were used. The results obtained show that the actual thermal sensations are in agreement with the thermal sensation provided, and that the thermal insulation of the garment must be adapted to the thermohygrometrics conditions of humid air, in order to prevent the failure of the bodyybody failure.

Keywords: Cold thermal environment, thermal sensation, EsConTer index, clothing insulation, weather maps.

\section{RESUMEN}

Riesgos para la salud en un ambiente termal frío: ropa y ola de frio - Este trabajo presenta un estudio de caso para un ambiente termal frío al aire libre en una región de coordenadas geográficas $40.67^{\circ} \mathrm{N}$ e $8.45^{\circ} \mathrm{W}$ realizado durante la primera quincena del mes de febrero de 2015. Se mantuvo ropa aislante. Fueron utilizados indicadores de sensación térmica y de aislamiento térmico. Los resultados obtenidos muestran que las sensaciones térmicas reales están de acuerdo con la sensación térmica proporcionada y que el aislamiento térmico de la ropa debe adaptarse a las condiciones termohigrométricas de aire húmedo, para evitar el fracaso del cuerpo.

Palabras clave: Ambiente termal frío, hipotermia, EsConTer, aislamiento ropa, mapas del tiempo.

\section{RESUME}

Risques pour la santé dans un environnent froid : vêtements et vague de froid - Cet article présente une étude de cas pour l'environnement thermique froid (air ambiant) à Sernado do Vouga (district of Aveiro), coordonnées géographiques $40.67^{\circ} \mathrm{N}$ e $8.45^{\circ} \mathrm{W}$, menée durant la première quinzaine du mois de février 2015. L'isolation thermique des vêtements a été maintenue. Les indicateurs Windchill et isolation thermique ont été utilisés. Les résultats obtenus montrent que les sensations thermiques réelles sont en accord avec la sensation thermique fournie, et que l'isolation thermique du vêtement doit être adaptée aux conditions thermo-hygrométriques, afin d'éviter la défaillance du corps.

Mots-clé: Environnement froid thermique, hypothermie, Indice EsConTer, isolation de vêtements, cartes météorologiques.

* O texto deste artigo corresponde a uma comunicação apresentada no IX Encontro Nacional de Riscos e II Forum ISCIA, tendo sido submetido em 30-09-2015, sujeito a revisão por pares a 18-03-2016 e aceite para publicação em 31-03-2016.

Este artigo é parte integrante da Revista Territorium, n. ${ }^{\circ} 23,2016,{ }^{\circ}$ RIscos, ISSN: 0872-8941. 


\section{Introdução}

O ambiente térmico pode ser designado como o conjunto de variáveis térmicas que influenciam as trocas de calor entre o ser humano e o ambiente que o rodeia. A ISO 7730 (2005) considera o conforto térmico como a satisfação expressa quando um indivíduo é sujeito a um determinado ambiente térmico.

Num ambiente térmico frio, o organismo pode acelerar o mecanismo para produzir mais energia sob a forma de calor. 0 vestuário também ajuda a manter a temperatura corporal. A hipotermia, que constitui a patologia geral devida ao frio acontece por falência da termorregulação. A sensação térmica depende de cada pessoa e é subjetiva, um ambiente pode ser termicamente confortável para uma pessoa e ser frio ou quente para outra (M. Talaia, 2015).

$\mathrm{Na}$ história da humanidade há dois episódios que devem ser recordados para ambiente térmico frio a céu aberto, e que foram atribuídos ao chamado "General do Inverno".

De acordo com a obra de J. F. Rolland (1972), Napoleão em 1812 deu ordens ao seu poderoso exército formado por cerca de 600.000 soldados e 180.000 cavalos para invadir a Rússia. Os russos, por seu lado evitaram o confronto direto e adotaram uma tática de guerra de "terra arrasada" (conforme iam se retirando, destruíam lavouras e tudo aquilo que podia ser útil para os invasores). Depois do incêndio de Moscovo, Napoleão ordenou a retirada a 18 de Outubro de 1812. O plano era regressarem pelo Sul, mas os russos cortaram o caminho e os militares foram forçados a voltar pelo mesmo caminho. 400.000 homens iriam perecer numa marcha de cerca de $1500 \mathrm{~km}$. Foi o tempo atmosférico, o famoso "General Inverno" quem conseguiu alcançar, no que se refere aos russos, as maiores vitórias. 0 Inverno registou temperaturas negativas de cerca de $-40^{\circ} \mathrm{C}$ provocando a morte aos soldados por falta de roupa adequada, cansaço, fome e frio, e os cavalos não tinham ferraduras adaptadas ao gelo, escorregavam e quebravam as patas. 0 "General Inverno" vencia assim o general Francês. Dos 600.000 homens apenas cerca de 30.000 retornaram a seus lares.

De acordo com P. Antill (2010) e Selecções do Reader's Digest (1975) em 22 de Junho de 1941, no âmbito da operação "Barbarossa" a maior operação militar de todos os tempos usando a táctica da guerra relâmpago, mais de 3 milhões de soldados nazistas romperam as fronteiras da União Soviética em três ofensivas paralelas. Estavam convencidos de que conseguiriam eliminar os soviéticos em poucos meses, antes do inverno chegar. Em 3 de Julho de 1941, Estaline decretou um comunicado de "terra arrasada" (cidades, casas e plantações deveriam ser destruídos ou queimados, para privar os invasores de seus recursos). A 2 de Outubro o exército alemão atravessa as defesas soviéticas. No entanto, alguns dias depois, as chuvas do outono começaram e o avanço alemão abranda até quase se deter, pois as empoeiradas e sujas estradas e pistas tinham-se transformado em lamaçais. Os soldados alemães começaram a, literalmente, afundar na lama e os tanques não se conseguiam movimentar assim como a força aérea não podia descolar (o óleo dos motores congelou e a visibilidade era muito baixa). 0 "General Inverno" chega e as temperaturas começam a diminuir abruptamente, registando-se cerca de $-50^{\circ} \mathrm{C}$, um frio glacial para o qual nem os soldados nem os armamentos alemães haviam sido preparados e por isso registaram-se consequências fatais. Abriram-se brechas nas posições avançadas e a máquina de guerra alemã resulta ineficaz nos terrenos pantanosos e sobre os rios gelados. Os desgastes causados pelas temperaturas negativas nos veículos e nos canhões ultrapassaram as previsões alemãs. A intensidade do "frio" custa o dobro de baixas em relação às causadas pelo inimigo. 0 irresistível "General Inverno" entra em cena tornandose um aliado das tropas soviéticas. Como se fosse pez a lama adere as rodas das carroças e dos camiões e em pouco tempo o poderoso exercito alemão fica como que atacado por paralisia, avançando lentamente com intenso esforço humano. A lama é substituída pelo gelo e neve. As tempestades de neve tornam-se intensas. Os soldados alemães estavam sem roupa adequada de inverno porque o seu envio havia sido negado pois era assumido conquistarem Moscovo, antes da chegada do Inverno. Contudo o inverno chega mais cedo e com grande intensidade forma geadas, ventos cortantes provenientes da Sibéria e tempestades de neve fazendo estragos no exército alemão e bloqueando o seu avanço. o "General Inverno" tinha entrado em ação derrotando as forças alemãs através do frio e fome. O inverno de 1941 foi excecionalmente duro como já não acontecia e provoca baixas aos soldados alemães estimando-se em cerca de 250.000 .

Estes dois episódios mostraram que um ambiente térmico frio a céu aberto pode suscitar stress térmico com consequências drásticas se não for usado vestuário com adequado isolamento térmico.

Neste estudo pretende-se analisar como os parâmetros termohigrométricos de um ambiente frio a céu aberto podem influenciar na sensação térmica real sentida por um indivíduo. De modo a ser analisada a sensação térmica real e compreender como o organismo reage às mudanças do tempo atmosférico, durante o estudo, foi usado o mesmo vestuário o que equivale a afirmar que se manteve o isolamento térmico. Foram analisados os mapas de tempo e investigada a presença de frente fria. Foi usado um índice térmico para prever a sensação térmica, uma escala térmica de cores para registar a sensação térmica real e um índice para prever o isolamento térmico do vestuário. Esta estratégica teve 
como objetivo testar e contribuir para a validação de metodologias já desenvolvidas, nomeadamente na aplicação do Índice EsConTer na definição da sensação térmica de um ser humano.

\section{Ambiente térmico frio}

O ambiente térmico é o conjunto das variáveis térmicas que influenciam as trocas de energia sob a forma de calor entre o ser humano e o meio que o circunda (A. Miguel, 2010). De acordo com a American Society of Heating Refrigeration and Air Conditions (ASHRAE, 2004), o conforto térmico pode ser definido como "o estado de espírito em que o indivíduo expressa satisfação em relação ao ambiente térmico" (ISO $7730,2005)$. No entanto a definição sugere um grau de subjetividade pois há dois vetores a considerar: um de cariz físico (ambiente térmico) e outro de cariz subjetivo (estado de espírito do indivíduo).

O conforto térmico acontece sempre que um indivíduo está numa condição de equilíbrio com o ambiente que o rodeia, em que a temperatura do corpo humano está próxima de $(37,0 \pm 0,8)^{\circ} \mathrm{C}$ sem que haja esforço adicional de termorregulação. Esta situação é chamada de ideal e corresponde a um ambiente neutro ou confortável. Se um ambiente térmico favorecer a saída dessas condições pode suscitar alterações fisiológicas no ser humano. Num ambiente térmico é importante que os ocupantes se sintam com sensação de conforto, caso contrário pode originar eventuais riscos para situações de desconforto térmico (E. R. Q. Costa et al., 2011).

$\mathrm{Na}$ prática é nas zonas consideradas de desconforto térmico que pode aparecer stress térmico, como por exemplo excesso de frio. Este pode suscitar o risco de acidentes e provocar danos à saúde (E. Grandjean, 1998).

No seu estudo K. C. Parsons (1993) concluiu que para um ambiente térmico frio existe uma relação inequívoca entre a temperatura registada das mãos e a "performance" ou destreza manual. Também T. Kim et al. (2007) referem que em trabalhos que exijam manipulação manual de cargas em ambientes severamente frios e durante períodos prolongados, há possibilidade de se registar uma redução na destreza manual. Nestas condições a eficiência do trabalho pode diminuir aumentando o risco de acidentes.

I. Holmér et al. (1999) referem que ambientes térmicos frios são caracterizados por condições ambientais que podem levar a uma condição de stress térmico por frio. O stress térmico por frio pode estar presente de diferentes maneiras por afetar o equilíbrio térmico de todo o corpo, nomeadamente as extremidades do corpo, a pele e os pulmões. Um dos mecanismos usados para responder ao stress térmico por frio baseia-se na adaptação, troca e ajuste de roupa, através da melhoria do isolamento térmico.
A hipotermia pode suscitar patologia geral devido ao frio gerando a falência da termorregulação. Entre as lesões provocadas pelo frio distinguem-se as que envolvem congelamento de tecidos (queimaduras e enregelamento) ou somente arrefecimento de tecidos (frieiras). 0 tempo de exposição prolongado ao frio pode ainda desencadear outras consequências para a saúde, nomeadamente ao nível do sistema cardiovascular e sistema respiratório. Num ambiente térmico frio a inalação de ar frio pode dar origem a episódios asmáticos devido à vasoconstrição (A. V. F. M. Oliveira, 2006; M. Talaia e D. Pina, 2015).

Também num ambiente térmico frio e quando há evidência de exposição crónica ao frio estão associadas lesões músculo-esqueléticas, sendo estas consideradas um fator de risco (L. Aasmoe et al., 2008). Quando a temperatura corporal interna diminui, o corpo arrefece, particularmente mãos, pés e rosto, e podem ocorrer algumas lesões dependendo da intensidade da natureza do frio e do tempo de exposição. Nesta situação, os movimentos ligeiros dos dedos e das mãos podem sofrer uma deterioração apreciável, mesmo com níveis moderados de exposição (I. Holmér, 2000).

Um ambiente térmico frio e húmido é mais desconfortável do que um ambiente térmico frio e seco, principalmente porque a humidade diminui o isolamento das roupas, com excepção da lã. A escolha de materiais a usar na confeção de vestuário é uma tarefa de planeamento cuidadosa que deve ter em atenção a proteção contra o vento e a humidade, além da evaporação do suor que se produz na pele. É oportuno afirmar que roupas impermeáveis não permitem a evaporação e por isso podem prejudicar a saúde. Com base no que se descreveu, uma proteção é considerada adequada quando permite a evaporação da pelicula de água que se forma na pele mas, não permite a penetração de chuva ou vento.

\section{Materiais e Métodos}

Neste estudo pretende-se analisar como parâmetros termohigrométricos de um ambiente frio a céu aberto podem influenciar a sensação térmica real sentida por um indivíduo. 0 vestuário usado foi mantido durante o período do estudo para se compreender como o organismo reagia às mudanças termohigrométricas.

Durante a primeira quinzena de fevereiro de 2015 foi realizado um estudo a céu aberto numa região definida pelas coordenadas geográficas de cerca de $40.67^{\circ} \mathrm{N}$ e $8.45^{\circ} \mathrm{W}$.

Foram registados dados termohigrométricos usando o instrumento de medida "Center 317 - Temperature Humidity Center" e mantido o mesmo vestuário para efeitos de comparação de sensação térmica, em situação de ambiente frio com hipotermia. Neste estudo foram usadas duas abordagens de recolha e tratamento de dados: (i), uma de carácter objetivo, com a recolha 
de dados termohigrométricos para prever a sensação térmica e isolamento térmico do vestuário através da aplicação de índices: (ii) outra de carácter subjetivo, através da aplicação de uma escala térmica de cores, com o objetivo de conhecer a sensação térmica real.

Foram registados os mapas de tempo e investigada a presença de frente fria. A presença de geada formada em algumas noites foi registada e foram feitas fotografias.

Foi usado um índice térmico para prever a sensação térmica, uma escala térmica de cores para conhecer a sensação térmica real e um índice para prever o isolamento térmico do vestuário.

O índice EsConTer (M. Talaia e H. Simões, 2009) foi formulado para prever a sensação térmica e é calculado aplicando a expressão,

$$
\text { EsConTer }=-3.75+0.103\left(T+T_{w}\right)
$$

onde $\mathrm{T}$ representa a temperatura do $\operatorname{ar}\left({ }^{\circ} \mathrm{C}\right)$ e $\mathrm{T}_{\mathrm{w}}$ a temperatura do termómetro húmido $\left({ }^{\circ} \mathrm{C}\right)$.

O valor do índice EsConTer está na gama de valores -3 a +3 e permite prever a sensação térmica de um ambiente de muito frio a muito quente. Numa escala térmica de cores, desenvolvida por Talaia e Rodrigues (2008), como se mostra na fig. 1, o indivíduo expressa a sua sensação térmica, ou seja, esta deve ser marcada com uma "cruz" na escala térmica de cores. A grande vantagem desta escala térmica de cores é a facilidade de leitura e interpretação da escala usada de $-3 \mathrm{a}+3$, incluindo valores decimais.

0 índice EsConTer tem um coeficiente de correlação de Pearson de 0.9895 face ao índice ITH (índice de temperatura e humidade) que tem sido largamente

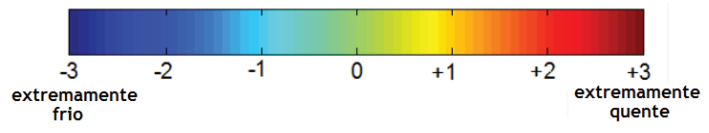

Fig. 1- Escala térmica de cores.

Fig. 1 - Thermal sensation scale. usado em estudos de ambiente térmico. 0 índice ITH foi modificado por S. Nieuwolt (1977) por introduzir como variáveis a medir com maior facilidade a temperatura do ar e a humidade relativa do ar e gera as mesmas considerações do índice EsConTer. $O$ índice ITH é calculado a partir da expressão,

$$
\mathrm{ITH}=0.75 \mathrm{~T}+\mathrm{T}(\mathrm{HR} / 500)
$$

em que $\mathrm{T}$ representa a temperatura do $\operatorname{ar}\left({ }^{\circ} \mathrm{C}\right)$ e $\mathrm{HR}$ a humidade relativa do ar (\%).

Na TABELA I são apresentados os valores de referência adaptados por M. Talaia et al. (2013) para uma vasta gama de valores de ITH, com base nas estratégias descritas no diagrama da Organização Mundial de Meteorologia (WMO, 1987).

0 índice de isolamento térmico, em unidades clo, desenvolvido pelo autor é apresentado neste estudo e o seu valor determina-se a partir do conhecimento da temperatura do termómetro húmido e do valor do EsConTer, usando a expressão,

$$
\text { Clo }=-0.035+0.057 \mathrm{~T}_{\mathrm{w}}-0.553 \mathrm{EsConTer}
$$

\section{Resultados e Discussão}

O índice EsConTer foi desenvolvido a partir de uma gama larga de registos para diferentes ambientes térmicos (frio, confortável e quente) e foi aceite para publicação na International Journal of Industrial Ergonomics, em Novembro de 2015, como uma nova visão e como um novo índice de fácil aplicação e interpretação (M. Morgado, $M$. Talaia e L. Teixeira, 2015). A fig. 2. mostra como o índice EsConTer é influenciado pela temperatura do ar.

A observação do gráfico da fig.2 mostra que os valores determinados neste estudo e para a sensação térmica real (círculos de cor vermelha) estão em concordância com valores de outros estudos quando se prevê a sensação térmica por aplicação do índice EsConTer (círculos de cor verde).

TABELA I - Valores para o ITH (fonte: M. Talaia et al., 2013).

TABLE I - Typical values of ITH (source: M. Talaia et al., 2013).

\begin{tabular}{|c|l|}
\hline ITH $\left({ }^{\circ} \mathrm{C}\right)$ & \multicolumn{1}{c|}{ Sensação térmica } \\
\hline ITH $<8$ & Demasiado frio (100\% dos indivíduos estão desconfortáveis) \\
\hline $8 \leq \mathrm{ITH}<21$ & Necessidade de aquecimento (50\% dos indivíduos estão desconfortáveis) \\
\hline $21 \leq \mathrm{ITH}<24$ & Confortável (100\% dos indivíduos estão confortáveis) \\
\hline $24 \leq \mathrm{ITH}<26$ & Necessidade de ventilação (50\% dos indivíduos estão confortáveis) \\
\hline $26 \leq \mathrm{ITH}$ & Demasiado quente (100\% dos indivíduos estão desconfortáveis) \\
\hline
\end{tabular}




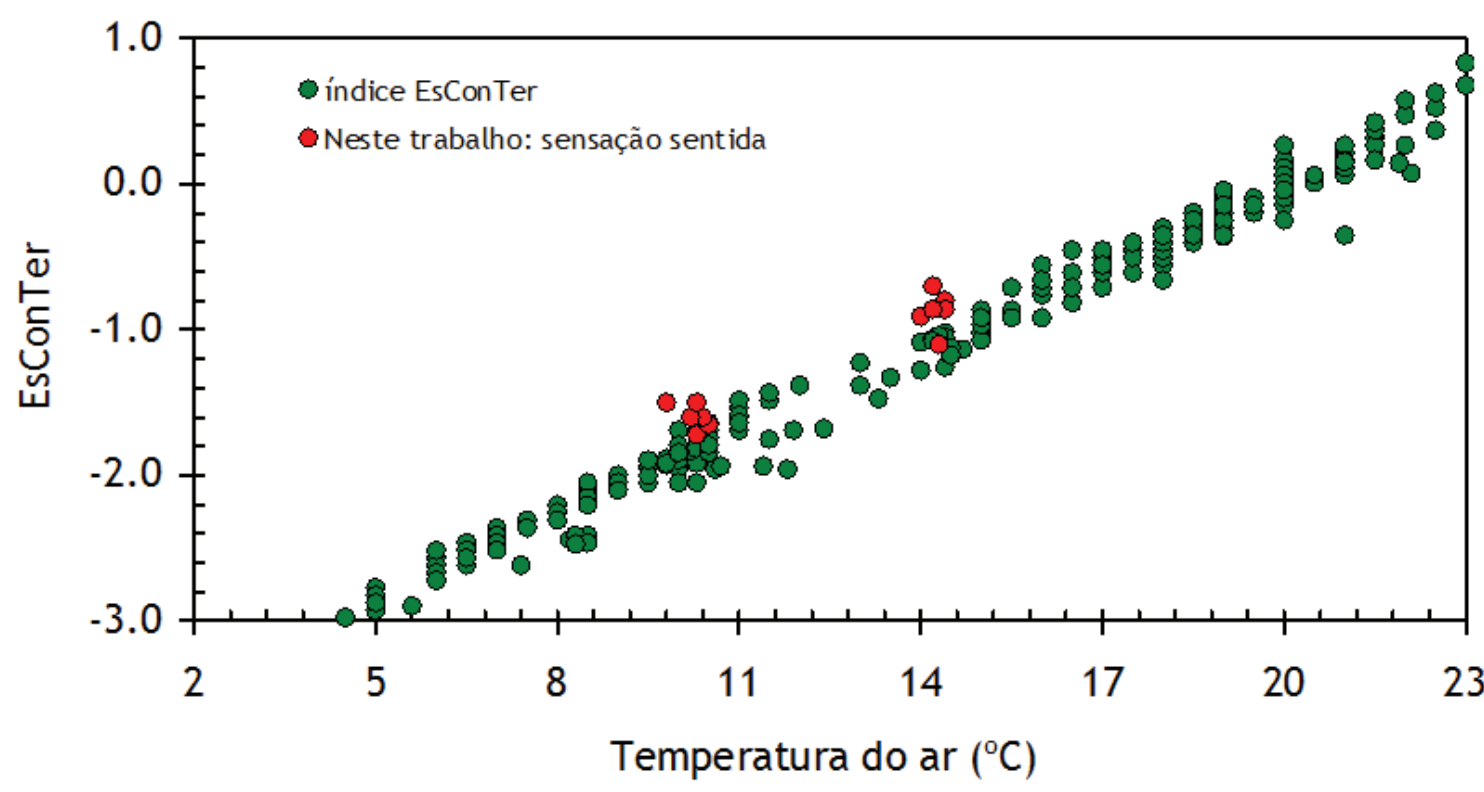

Fig. 2 - EsConTer versus temperatura do ar.

Fig. 2 - EsConTer versus air temperature.

A fig. 3 mostra como o valor do isolamento térmico do vestuário, em unidades de clo, é influenciado pela dinâmica das estações do ano, ou seja as condições termohigrométricas do ar húmido influenciam o bemestar do ser humano em diferentes ambientes térmicos.

A observação do gráfico da fig. 3 mostra diferentes informações: os círculos de cor vermelha representam valores registados para o verão; os círculos de cor amarela representam valores registados para a primavera; os círculos de cor azul clara representam valores registados para o outono; os círculos de cor azulescura representam valores registados para o inverno; os losangos de cor negra os valores de clo previstos; os triângulos de cor azul clara os valores de clo usado neste trabalho e os triângulos de cor verde os valores de clo segundo a norma ISO 7730 (2005).

Na fig. 3 o valor usado de clo para o estudo e determinado pela expressão desenvolvida a partir da temperatura do termómetro húmido e pelo índice EsConTer e apresentada neste trabalho (composto por camisola,

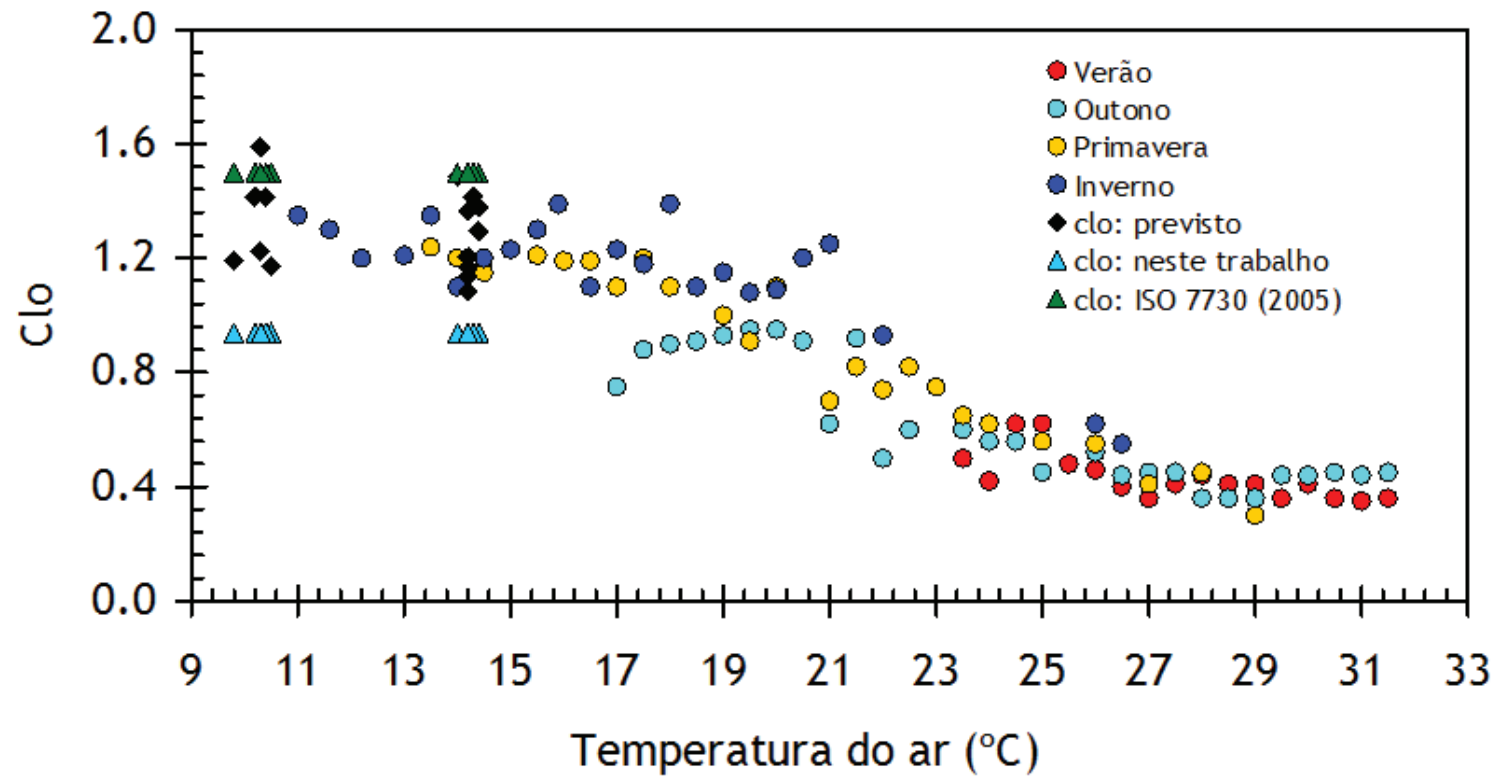

Fig. 3 - Tendência do valor de Clo com a temperatura do ar (adotado de Liu et al., 2012).

Fig. 3 - Clothing insulation tendencies with air temperature (adopted from Liu et al., 2012). 
camisa, cueca, meias, calças de algodão e sapatos) é inferior ao previsto e sugerido pela norma ISO 7730 (2005) o que sugere stress térmico em ambiente térmico frio a céu aberto. A sensação térmica sentida foi de frio forte em todo o corpo, mais acentuado nas mãos, pés, cotovelos e costas. Uma solução para aumentar o valor de clo usado passava pelo uso de um casaco, botas e calças adequadas. A norma ISO 7730 (2005) apresenta algumas tabelas de valores típicos para o clo sugerindo para diferentes ambientes térmicos combinações de uso de roupa. Os valores de clo previstos neste estudo e da norma ISO 7730 (2005) estão concordantes com os valores indicados para o inverno por J. Liu et al. (2012), como se mostra na fig. 3 .

A fig. 4 mostra como valor de clo e EsConTer são influenciados pela temperatura do ar. Deve-se chamar a atenção que há ligações termodinâmicas entre a temperatura do ar, a humidade relativa do ar, a temperatura de ponto de orvalho e a temperatura do termómetro húmido através da aplicação de formulas disponíveis na literatura da especialidade, nomeadamente em livros da meteorologia física. Os círculos de cor azul clara representam os valores de clo previstos; os círculos de cor negra os valores previstos pela aplicação do índice EsConTer; os triângulos de cor azul clara os valores de clo usados neste trabalho; a linha de ajuste de cor azul a tendência do valor de clo e a linha de ajuste de cor negra a tendência dos valores de sensação térmica, por aplicação do método dos desvios mínimos quadrados. Inequivocamente os valores indicados mostram uma sensação térmica de stress térmico quando o ambiente término regista temperaturas inferiores a $6.5^{\circ} \mathrm{C}$. Nestes casos 0 isolamento término em unidades de clo deve aumentar para se registar uma proteção adequada do corpo.
A título de exemplo, a fig. 5 mostra um mapa de tempo para o dia 6 de Fevereiro de 2015 durante o período de estudo. Este mapa de tempo foi obtido a partir da consulta no sítio de informação gratuita diária http://www.wetterzentrale.de/topkarten/tkfaxbraar.htm. Neste dia foram registados valores às $8 \mathrm{~h} 00$ nomeadamente uma temperatura do ar de $7.4^{\circ} \mathrm{C}$, uma humidade relativa do ar de $47.1 \%$ e uma sensação de stress térmico de ambiente muito frio de -2.6 , e às 20 h00 uma temperatura de $10.6^{\circ} \mathrm{C}$ e uma humidade relativa de $53.3 \%$ e uma sensação de stress térmico de ambiente de frio -2.0. Esta ligeira melhoria é justificada pela radiação solar direta que intersecta a superfície da terra e voltada para o Sol (fonte de luz e calor).

A observação das linhas indicadas no gráfico da fig. 5 mostram que a zona de estudo, marcada no mapa de tempo com um círculo de cor vermelha, estava com a influência de uma passagem de frente fria. $O$ valor indicado pelas linhas isobáricas permite concluir que havia influência de uma massa de ar com características de muito fria. A sua origem é indicada através das setas traçadas a cor azul que mostram a direcção e sentido do vento.

$\mathrm{Na}$ fig. 6 as duas imagens mostram que durante a noite, houve formação de geada por se terem registado temperaturas negativas. Na noite de 6 de Fevereiro o arrefecimento nocturno através da emissão de energia no infravermelho registou nas superfícies uma temperatura inferior à temperatura de ponto de orvalho de $1.5^{\circ} \mathrm{C}$ e suscitou a formação de orvalho ou película de água que devido ao registo de temperaturas negativas formou a geada.

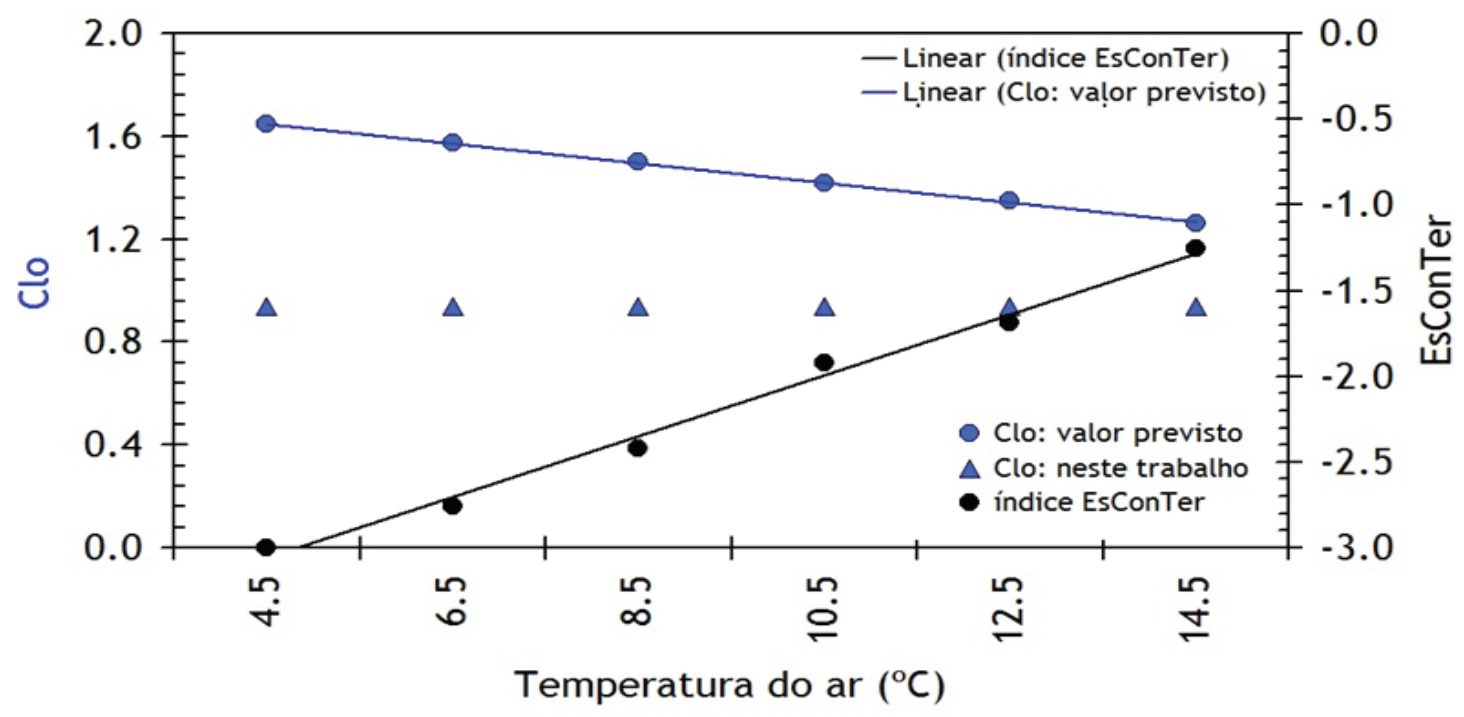

Fig. 4 - Influência da temperatura no clo e na sensação térmica real e prevista.

Fig. 4 - Temperature influence on clo and in real and planned thermal sensation. 
Conclui-se que um ambiente térmico a céu aberto com características de frio a muito frio pode aumentar o risco para a saúde pública pois a sensação térmica é de stress térmico de muito frio [na escala térmica da norma ISO 7730 (2005) de -2.0 a -3.0] o que favorece condições gravosas de hipotermia. Nestes ambientes a protecção de vestuário adequado, na unidade térmica de clo, é muito importante para manter o balanço energético do corpo em condições de saúde.

\section{Conclusão}

Os resultados obtidos neste estudo mostram que um ambiente térmico frio a muito frio pode suscitar stress térmico e risco para a saúde pública se não houver uma preocupação em usar vestuário adequado em termos de isolamento térmico. Esta situação foi vivenciada através do chamado "General Inverno" nos dois episódios da história descritos na introdução deste estudo.

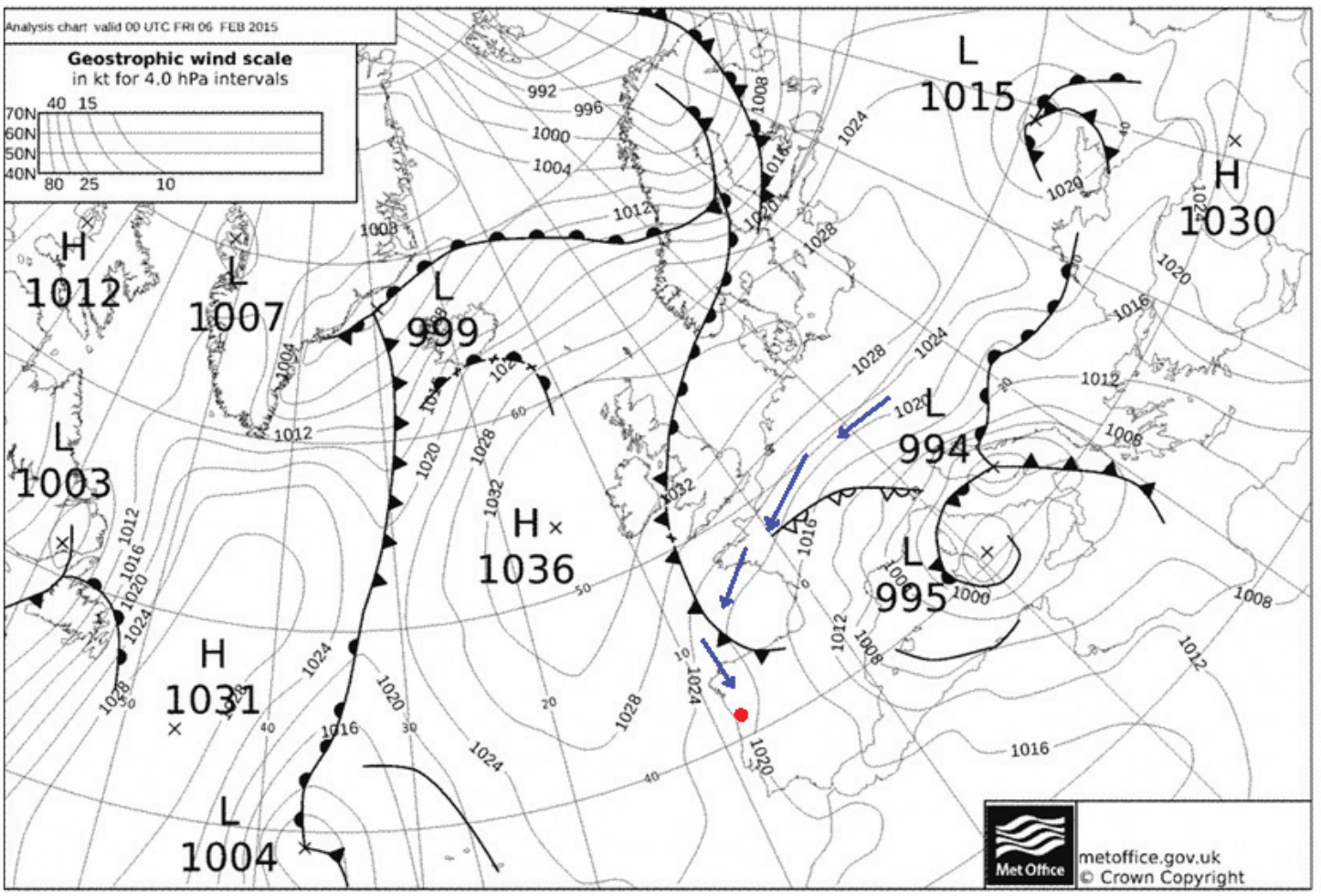

Fig. 5 - Mapa de tempo.

Fig. 5 - Weather map.
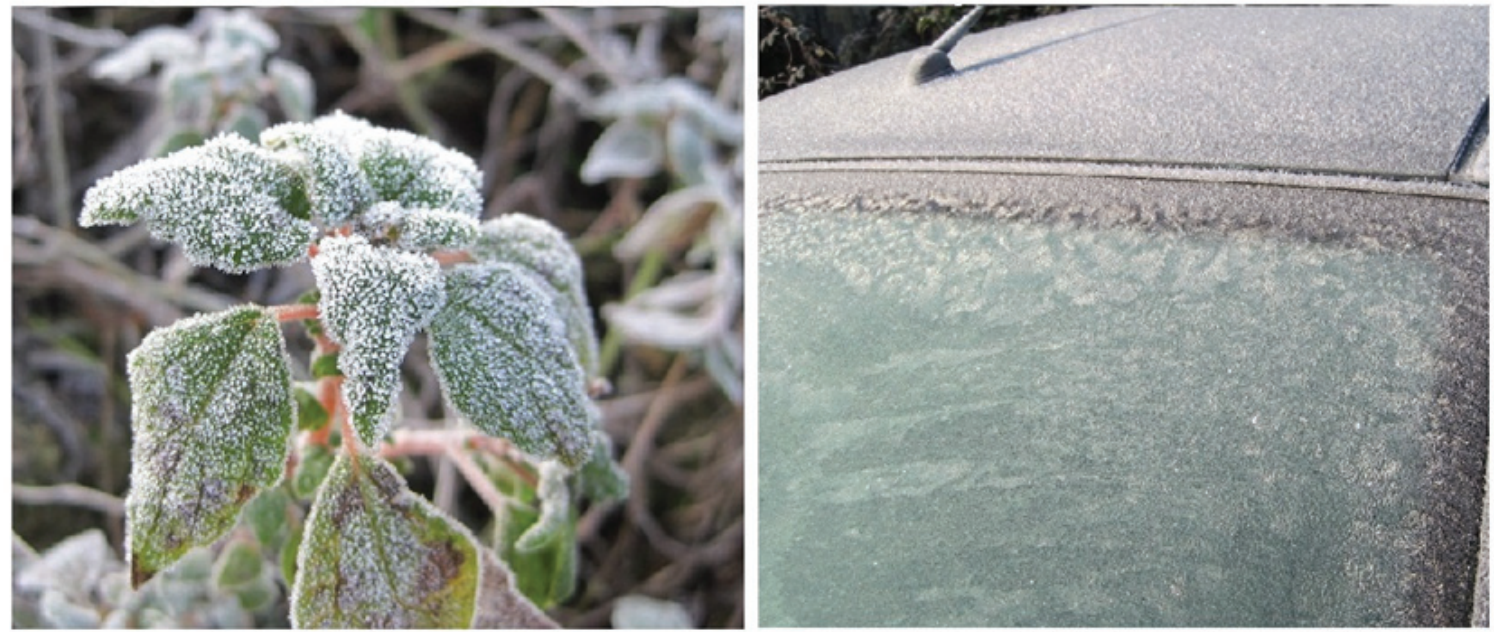

Fig. 6 - Formação de geada.

Fig. 6 - Frost formation. 
Neste estudo o uso do mesmo isolamento térmico (mesmo vestuário) mostrou que a sensação térmica real ou sentida é influenciada pelas condições termohigrométricas do ar húmido. Este valor suscitou condições de frio acentuado em todo o corpo, mais acentuado nas mãos, pés, cotovelos e costas. Esta situação mostrou que o isolamento térmico em unidades de clo deveria ter sido melhorado, de modo a não limitar a destreza motora. No entanto considerou-se importante manter o mesmo vestuário para se ter a percepção da agressividade de diferentes níveis de hipotermia. Tevese o cuidado, em todos os registos a céu aberto, de não se estar demasiado tempo exposto a agressividade das condições se stress térmico ao frio.

Este trabalho mostrou que a perceção da sensação térmica está de acordo com a previsão da sensação térmica através da aplicação do índice EsConTer.

Os mapas de tempo mostraram presença de frente fria e a orientação das linhas isobáricas indicaram a fonte da massa de ar com características de fria. A formação de geada em diferentes noites comprovou o registo de temperaturas negativas durante noites.

\section{Referências bibliográficas}

Aasmoe, L., Bang, B., Egeness, C. e Lãchen, M. L. (2008). Musculoskeletal symptoms among seafood production workers in North Norway. Occupational medicine, 58(1), 64-70.

Antill, P. (2010). Grandes Batalhas - Estalinegrado 1942 - A Guerra Muda de Rumo. Osprey Publishing, RBA Coleccionables S.A., Barcelona, Espanha, pp.96.

ASHRAE (2004). Standard 55. Thermal environmental conditions for human occupancy. Atlanta.

Costa, E. R. Q., Baptista, J. S., Diogo, M. T. e Magalhães, A. B. (2011). Hot thermal environment and its impact in productivity and accidents. Artigo apresentado em International Symposium on Occupational Safety and Hygiene - SHO 2011.

Grandjean, E. (1998). Manual de ergonomia: adaptando o trabalho ao homem. Bookman.

Holmér, I. (2000). Cold stress: Part II - The scientific basis (knowledge base) for the guide. Elsevier Ergonomics Book Series, 1, 357-365.

Holmér, I., Granberg, P. O e Dahlstrom, G. (1999). Ambientes fríos y trabajo com frío. Enciclopedia de Seguridad y Salud en el trabajo. OIT. Cap.42, 32-60.

ISO 7730 (2005). Ergonomics of the thermal environmentAnalytical determination and interpretation of thermal comfort using calculation of the PMV and PPD indices and local thermal comfort criteria. International Organization for Standardization.

Kim, T., Tochihara, Y., Fujita, M. e Hashiguchi, N. (2007). Physiological response and performance of loading work in a severely cold environment. International Journal of Industrial Ergonomics, 37(9), 725-732.
Liu, J., Yao, R., Wang, J. e Li, B. (2012). Occupants' behavioral adaptation in workplaces with noncentral heating and cooling systems. Applied Thermal Engineering, 35, 40-54.

Lorsch, H. G. (1994). The impact of the building indoor environment on occupant productivity part2: Effect of temperature. ASHRAE Trans., 100(2), 895-901.

Miguel, A. S. (2010). Manual de Higiene e segurança no trabalho $\left(11^{\mathrm{a}}\right.$ ed.): Porto.

Morgado, M., Talaia, M. e Teixeira, L. (2015). A new simplified model for evaluating thermal environment and thermal sensation: An approach to avoid occupational disorders, International Journal of Industrial Ergonomics, http://dx.doi.org/10.1016/j. ergon.2015.11.001.

Nieuwolt, S. (1977). Tropical climatology. Wiley.

Oliveira, A. V. F. M. (2006). Estudo de ambientes térmicos frios: desenvolvimentos experimentais $e$ avaliação de condições de trabalho. Doutoramento em Ciências de Engenharia Mecânica na especialização de Climatização e Ambiente, Faculdade de Ciências e Tecnologia da Universidade de Coimbra, Departamento de Engenharia Mecânica.

Parsons, K. C. (1993). Human thermal environments. London; Bristol, PA: Taylor e Francis.

Rolland, J.F. (1972). A queda do Império - A Rússia e a Revolução Francesa. Historama, A Grande Aventura do Homem. Editora Codex, Ltda. Buenos Aires, Argentina. Grolier, 9: 153-154.

Selecções do Reader's Digest (1975). Grande Crónica da Segunda Guerra Mundial. Vol 1, Selecções do Reader's Digest S.A.R.L., Lisboa, Portugal, pp.482.

Talaia, M. (2015). Riscos para a saúde: o vestuário numa onda de frio. Livro de resumos do IX Encontro Nacional de Riscos e II Forum de Riscos e Segurança do ISCIA. RISCOS GLOBAIS E SOCIEDADE DE RISCO. 15 de Maio de 2015. Instituto Superior das Ciências da Informação e da Administração, Aveiro, Portugal, 34.

Talaia, M., Meles, B. e Teixeira, L. (2013). Evaluation of the thermal comfort in workplaces - a study in the metalworking industry. Occupational Safety and Hygiene. London: Taylor e Francis Group; 473-477.

Talaia, M. e Pina, D. (2015). Circulation weather types and their Influence on the risk of respiratory disease, Territorium, 23 (in press).

Talaia, M. e Rodrigues, F. (2008). Conforto e stress térmico: uma avaliação em ambiente laboral. In Silva Gomes, J. F., António, C. C., Clito F. Afonso, C. F \& Matos, A. S.. Edição INEGI (Ed.), CLME'2008 II CEM. $8^{\circ}$ Congresso Luso-Mocambicano de engenharia e $2^{\circ}$ Congresso de Engenharia de Moçambique. Maputo. Artigo com15 páginas.

Talaia, M. e Simões, H., 2009. EsConTer: um índice de avaliação de ambiente térmico. In: V Congresso Cubano de Meteorologia. SometCuba, Sociedade de Meteorologia de Cuba; 1612-1626.

WMO (1987). World Climate Program Applications, Climate and Human Health. World Meteorological Organization. 

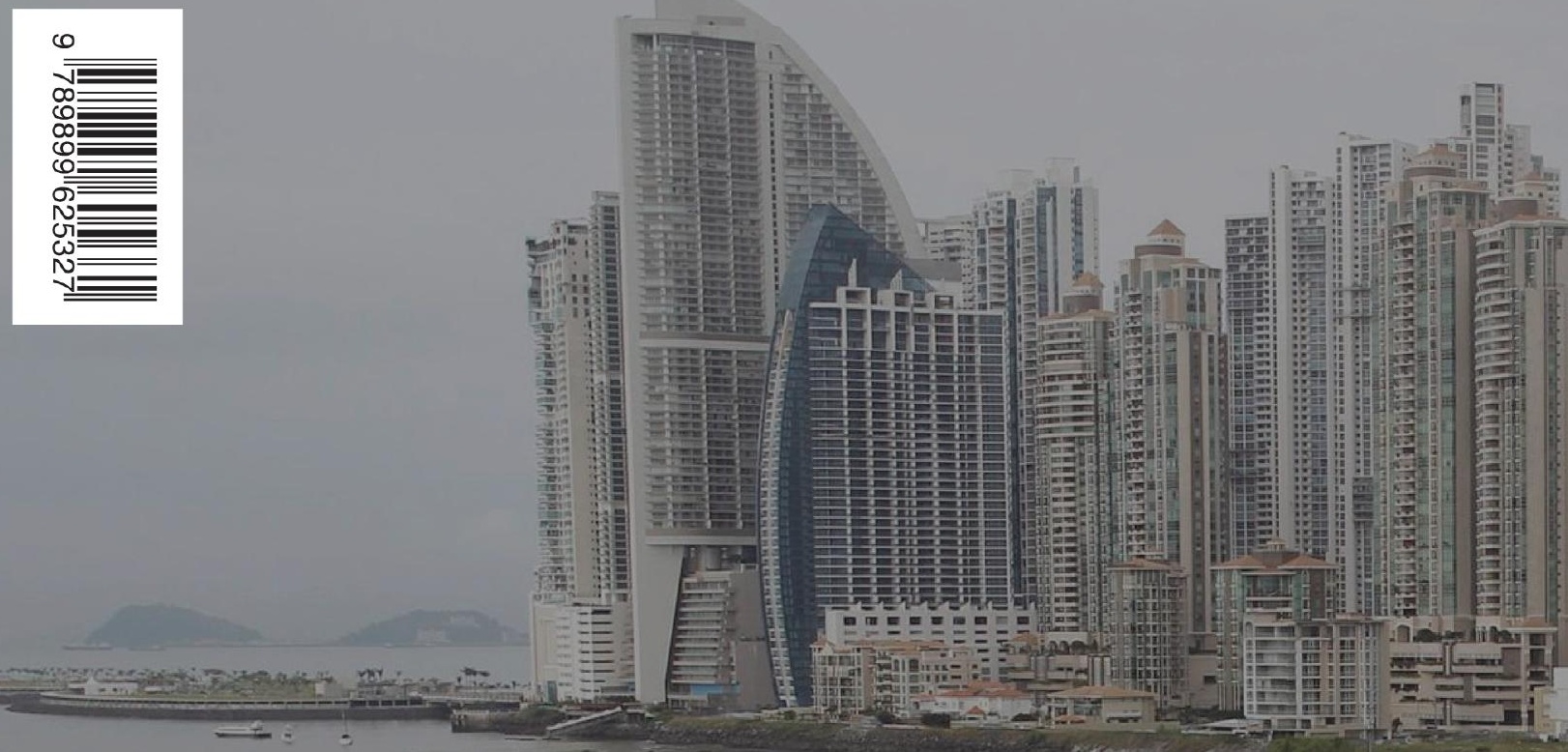

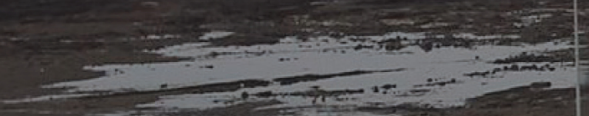

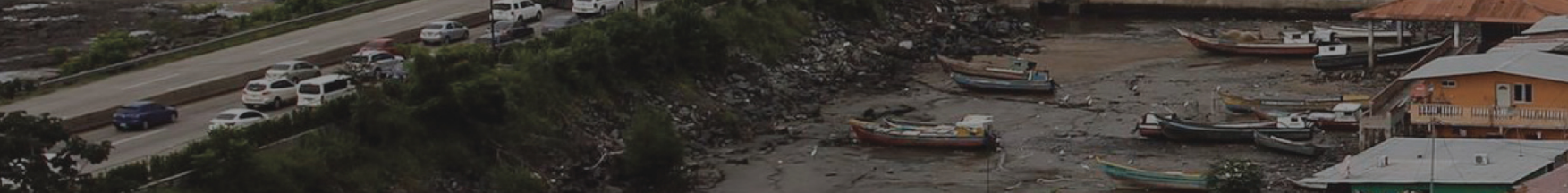

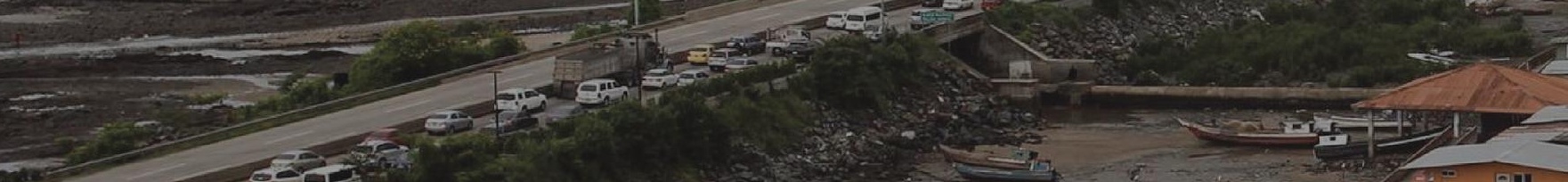
inse- $n=$ Riscos I I I

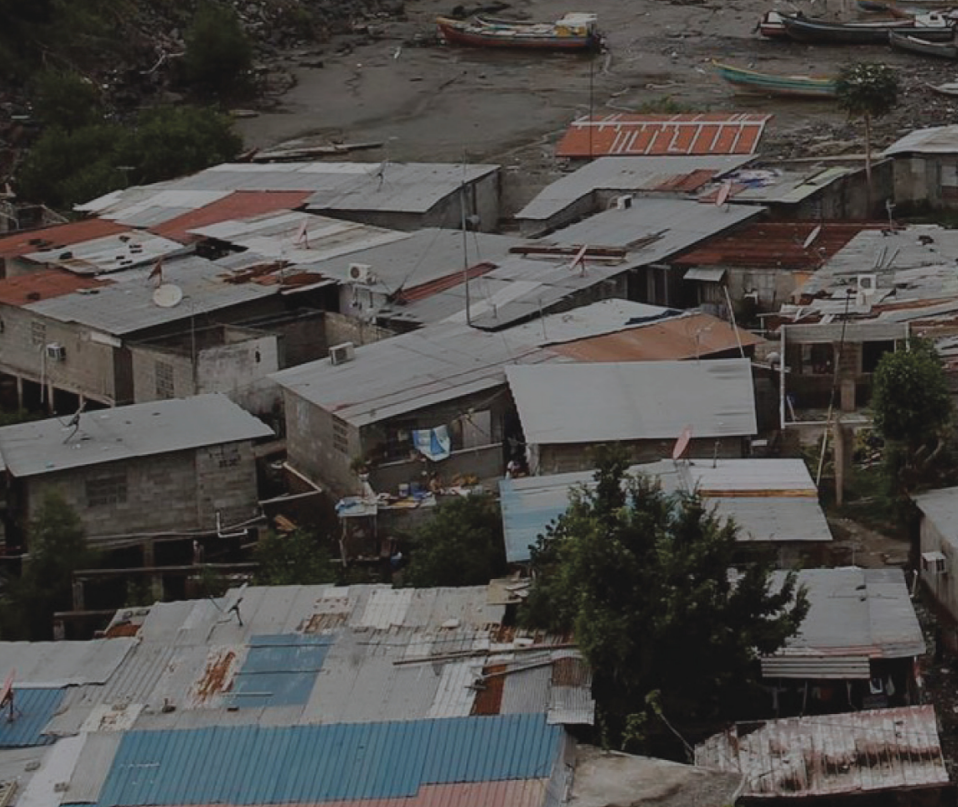

